\title{
Sociodemographic Profile, Contraceptive Practice and Awareness of HIV Infection among Unmarried Postpartum Women in a Tertiary Centre in Malaysia
}

\author{
Mustafa KBa ${ }^{\mathrm{a}}$, Ibrahim $\mathrm{N}^{\mathrm{b}}$, Noraziana AW' ${ }^{\mathrm{a}}$, Ayu ASa, Suhaiza $\mathrm{A}^{\mathrm{a}}$, Awang $\mathrm{M}^{\mathrm{a}}$ \\ ${ }^{a}$ Obstetrics and Gynecology Department, Kulliyyah of Medicine, International Islamic University \\ Malaysia(IIUM), Pahang, Malaysia. \\ ${ }^{b}$ Obstetrics and Gynecology Department, Hospital Tengku Ampuan Afzan, Kuantan, Pahang, Malaysia
}

\begin{abstract}
Introduction: To describe the sociodemographic profile, contraceptive practice, and awareness of HIV infection among unmarried post partum women in the biggest government hospital in Pahang. Methods: A cross sectional questionnaire-proforma-based study was conducted for one year duration from August 2010 until July 2011 by identifying and recruiting all the unmarried women upon admission for delivery. Basic information were obtained from the use of patients' case notes, and further related and necessary information were obtained from a direct face-to-face interview based on a proforma. Results: A total of 121 unmarried women were identified and recruited. The age ranged from 13 to 36 years with a mean age of 21.6 years. $31.4 \%$ were teenagers. Only $16 \%$ of patients have tertiary education, and $2.5 \%$ never had any formal education. About one third of the women were smokers or ex-smokers, $7.5 \%$ had consumed alcohol, but none denied ever use of any recreational drugs. Almost $9 \%$ has prior history of being sexually assaulted. About three quarter of the women never used any contraceptive method. Majority of the patients $(85.1 \%)$ were aware of HIV transmission risk; $75 \%$ never had any antenatal checkup or booked at late gestation (> 20 weeks); and $45.8 \%$ were not aware of any support groups for single mothers. Conclusion: Single unmarried women are associated with disadvantaged sociodemographic profile. Contraceptive practice was also very low despite significant awareness towards risk of HIV infection. Further follow up, support and care should be offered to these women.
\end{abstract}

KEYWORDS: unmarried mothers, unwanted pregnancies, sociodemography, HIV awareness, contraceptive use

\section{INTRODUCTION}

The issue of abandonment of babies as well as infanticide in Malaysia has been repeatedly highlighted in the media. There has been a spike in the number of baby-dumping incidences since 2010. After dropping from 102 cases in 2008 to 79 in 2009, the figure increased to 91 and 98 in 2010 and 2011 respectively. Up till July 2012, 31 cases were reported by Malaysian Women, Family and Community Development Ministry Deputy Secretary-General Harjeet Singh. ${ }^{1}$ In many cases these are as a result of unwanted pregnancies from unmarried mothers.

\section{Corresponding author:}

Dr Kamarul Bahyah Mustafa Obstetrics \& Gynaecology Department, Level 4, Kulliyyah of Medicine, Jalan Hospital Campus, International Islamic University Malaysia 25100 Kuantan, Pahang

Malaysia

Email: drkamarulbahyah@yahoo.co.uk

Office phone: $+609-5706000$

Fax No: $+609-5163764$
A study in China has shown that, more and more adolescents are engaging in premarital sex. Of those who are sexually active, one-quarter had been pregnant or had impregnated a partner. ${ }^{2}$ Social factors, such as poverty, a lack of education, an inadequate family support predispose them at high risk for sexually transmitted infections (STIs), unsafe abortions, labor, and delivery complications. ${ }^{3}$ In Malaysia, the incidence of premarital sexual activity among youths aged 18 to 24 years old is $6.5 \% .{ }^{4}$ The effect on the early sexual exposure especially with regards to STIs and cervical cancer, as well as maternal health care during the unwanted pregnancy is of paramount consideration. This is because unmarried women are also known to have greater risks of adverse pregnancy outcomes than married women. ${ }^{5}$ Unfortunately they also tend to have poor antenatal check up or no antenatal check up at all. ${ }^{6}$

With regards to infanticide or neonaticides, the most frequent perpetrator is a victim's parent or stepparent. ${ }^{7,8,9}$ Neonaticidal mothers are often young, unmarried women with unwanted pregnancies who received no antenatal care. The mothers were often poor, socially isolated, full-time caregivers, who were victims of domestic violence or had other relationship 
problems. Disadvantaged socioeconomic backgrounds and primary responsibility for the children were common. ${ }^{9}$

The same pattern could be occurring even in the conservative community in Malaysia. Obtaining a reliable statistic however is very difficult as our society is very reserved in revealing this private information even when confidentiality is assured. A number of cases also may not be able to be detected especially when the deliveries are conducted in private hospital and wrong information is provided with regards to the patients' marital status. Quite a number also had their deliveries in places where no skill birth attendants are available. This is not surprising because having a child out of wedlock is not only frown upon from the religious perspective, it also carries a social stigma; thus the women will try their best to conceal it from the society.

The aim of the study was to identify the sociodemographic information, HIV, and contraceptive awareness of the women at risk namely the unmarried mothers who come and delivered at our centre. Identifying this information in the local community might allow the inherent problems to be targeted, addressed and corrected to ensure better care for both mothers and babies, and the community as a whole.

\section{MATERIALS AND METHODS}

This study was a cross sectional questionnaireproforma-based study conducted for one year from August 2010 until July 2011 at Hospital Tengku AmpuanAfzan Kuantan, Pahang - the largest and the main hospital serving the largest state of Peninsular Malaysia. All unmarried women were identified upon admission for delivery based on their marital history. They were approached soon after delivery and adequate rest, in the post natal ward, or gynaecology ward in cases of perinatal death, and a set of questionnaireproforma would be filled up by a researcher. This session will also be used to counsel and advice patients regarding their future plan in terms of care of the babies, abstinency/ contraception, or support groups.

Inclusion criteria: All unmarried women who came for delivery in the centre during the study period would be included in the study unless they refused to do so. In cases where patient refuses to answer the questionnaire, the basic sociodemographic data would be captured from the case notes but detail questioning based on the proforma will be omitted. For patients below 18 years of age, consents were obtained from the parents or guardian. Exclusion criteria: the unmarried women who were not consented to the study; too ill to participate; or those with severe mental health problem.

All participants gave written inform consent before the study began. The research protocol was approved by IIUM Ethics Committee, Clinical research Centre HTAA, and Ethical \& Medical Research Committee (JEPP), Ministry of Health, Malaysia.

\section{RESULTS}

During the one year study period, out of 9994 women who were admitted for deliveries, 121 (1.21\%) were identified as unmarried, and were recruited. All fulfilled the inclusion criteria. Majority of the women who came for deliveries during the period were Malays $(83.2 \%)$ which is also reflected in the unmarried women group (90.1\%) (Table I).

Table I. Sociodemographic characteristics of the unmarried women

\begin{tabular}{|c|c|c|c|c|}
\hline \multirow[t]{2}{*}{ Ethnicity } & \multicolumn{2}{|c|}{ Total deliveries } & \multicolumn{2}{|c|}{ Unmarried women } \\
\hline & $\mathrm{N}$ & $\%$ & $\mathrm{n}$ & $\%$ \\
\hline Malay & 8319 & 83.2 & 109 & 90.1 \\
\hline Chinese & 439 & 4.4 & 3 & 2.5 \\
\hline Indian & 183 & 1.8 & 1 & 0.8 \\
\hline Orang Asli & 563 & 5.6 & 7 & 5.8 \\
\hline Foreigner & 490 & 4.9 & 1 & 0.8 \\
\hline Total & 9994 & 100 & 121 & 100 \\
\hline
\end{tabular}

The youngest maternal age was 13 and the oldest 36 with a mean age of 21.6(4.3) years. Teenagers (age 10-19) comprised $31.4 \%$ of the study group. (Table II). Only $16 \%$ of patients have education beyond their primary and secondary school, and $2.5 \%$ never had any formal education. $31.4 \%$ of the women were smokers or ex-smokers, $\mathbf{7 . 4 \%}$ ever consumed alcohol, however none ever use any recreational drugs. Majority of the patients were working women $(96.7 \%)$ - either part time/ full time/ odd jobs however, mostly earn less than RM 1000 a month (90.9\%); and 57\% earn less than RM500 which is considered a very poor income. The 
income of the biological father of the baby is also considered low with $64.5 \%$ earn less than RM 2000. This is also the same in the women's parents - $67.7 \%$ earn less than RM 2000 monthly. All these indicate that the majority of the respondents in this centre come from a low socioeconomic status group. $90.9 \%$ of the women became pregnant after sexual debut with either their boyfriend or their fiancée, and $5 \%$ had their sexual encounter with a complete stranger.

Table II. Sociodemographic characteristics of the unmarried women

\begin{tabular}{|c|c|c|}
\hline Criterias & $\mathrm{N}$ & $(\%)$ \\
\hline \multicolumn{3}{|l|}{ Age (years) } \\
\hline Mean (SD) ${ }^{a}$ & $21.6(4.29)$ & \\
\hline$<20$ & 38 & $(31.4)$ \\
\hline $20-25$ & 67 & $(55.4)$ \\
\hline $26-30$ & 9 & $(7.4)$ \\
\hline $31-35$ & 6 & $(5.0)$ \\
\hline$>35$ & 1 & $(0.8)$ \\
\hline \multicolumn{3}{|l|}{ Religion } \\
\hline Islam & 111 & $(91.7)$ \\
\hline Budha & 3 & $(2.5)$ \\
\hline Hindu & 0 & (0) \\
\hline Christian & 2 & $(1.7)$ \\
\hline Others & 5 & $(4.1)$ \\
\hline \multicolumn{3}{|l|}{ Formal education } \\
\hline None & 3 & $(2.5)$ \\
\hline Primary & 8 & $(6.6)$ \\
\hline Secondary & 89 & (73.6) \\
\hline Tertiary & 19 & (15.7) \\
\hline No information & 2 & $(1.7)$ \\
\hline \multicolumn{3}{|l|}{ Working status } \\
\hline Working & 117 & $(96.7)$ \\
\hline Not working & 4 & $(3.3)$ \\
\hline \multicolumn{3}{|l|}{ Respondent's monthly income } \\
\hline$<$ RM 500 & 69 & $(57.0)$ \\
\hline RM 500 - RM 1000 & 41 & (33.9) \\
\hline$>$ RM 1000 & 7 & $(5.8)$ \\
\hline No information & 4 & $(3.3)$ \\
\hline \multicolumn{3}{|l|}{ Substance abuse } \\
\hline \multicolumn{3}{|l|}{ Smoking } \\
\hline Yes & 38 & $(31.4)$ \\
\hline No & 83 & $(68.6)$ \\
\hline \multicolumn{3}{|l|}{ Alcohol } \\
\hline Yes & 9 & $(7.4)$ \\
\hline No & 112 & $(92.6)$ \\
\hline \multicolumn{3}{|l|}{ Illegal drugs } \\
\hline Yes & 0 & $(0)$ \\
\hline No & 121 & $(100)$ \\
\hline \multicolumn{3}{|c|}{ No. of siblings (including respondents) } \\
\hline $1-5$ & 60 & $(49.6)$ \\
\hline $6-10$ & 55 & $(45.5)$ \\
\hline$>10$ & 3 & $(2.5)$ \\
\hline Unknown & 3 & $(2.5)$ \\
\hline \multicolumn{3}{|c|}{ Marital status of respondents' parents } \\
\hline Married & 74 & $(61.2)$ \\
\hline Divorced $( \pm$ remarried) & 13 & $(10.7)$ \\
\hline Widow/widower & 31 & $(25.6)$ \\
\hline Unknown & 3 & $(2.5)$ \\
\hline \multicolumn{3}{|c|}{ Monthly income of respondents' parents } \\
\hline$<\mathrm{RM} 1000$ & 43 & $(35.5)$ \\
\hline RM1000 - < 2000 & 39 & $(32.2)$ \\
\hline RM2000 - < 3000 & 6 & (5) \\
\hline $\mathrm{RM} 3000-<4000$ & 2 & $(1.7)$ \\
\hline RM4000 - < 5000 & 1 & $(0.8)$ \\
\hline $\mathrm{RM} \geq 5000$ & 2 & $(1.7)$ \\
\hline No information & 28 & $(23.1)$ \\
\hline \multicolumn{3}{|c|}{ Relationship between respondents and the 'claimed' biological father of the baby } \\
\hline Boyfriend & 98 & $(81)$ \\
\hline Fiancee & 12 & (9.9) \\
\hline Others & 6 & $(5.0)$ \\
\hline Unknown & 5 & $(4.1)$ \\
\hline
\end{tabular}


With regards to the pregnancy and delivery information (Table III), majority are of para 1 (83.5\%) but even there are patients with para 4, 5, and 6. $13.2 \%$ of the women admitted to attempting to terminate this pregnancy though unsuccessfully. A high number of the patients $(71.1 \%)$ either never booked the pregnancy or book their pregnancy late. Despite the poor antenatal care and follow up, majority of the patients planned to care the newborn themselves with or without the help from her family or the biological father's family.

Table III. Pregnancy \& delivery information

\begin{tabular}{|c|c|c|c|}
\hline Variable & $\mathbf{N}$ & & (\%) \\
\hline \multicolumn{4}{|l|}{ Parity (upon delivery) } \\
\hline 1 & 101 & & $(83.5)$ \\
\hline 2 & 9 & & (7.4) \\
\hline 3 & 5 & & $(4.1)$ \\
\hline 4 & 4 & & (3.3) \\
\hline 5 & 1 & & $(0.8)$ \\
\hline 6 & 1 & & $(0.8)$ \\
\hline \multicolumn{4}{|c|}{ Attempted to terminate the pregnancy } \\
\hline Yes & 16 & & $(13.2)$ \\
\hline No & 101 & & $(83.5)$ \\
\hline No information & 4 & & (3.3) \\
\hline \multicolumn{4}{|l|}{ Antenatal Booking status } \\
\hline Early booker ( $\leq 20$ weeks) & & 29 & $(24.0)$ \\
\hline Late booker & & 67 & $(55.4)$ \\
\hline Never booked & & 19 & $(15.7)$ \\
\hline No information & & 6 & $(5)$ \\
\hline \multicolumn{4}{|l|}{ Booking $=$ First antenatal check up } \\
\hline \multicolumn{4}{|c|}{$\begin{array}{l}\text { Late booker = booking for antenatal care after } 20^{\text {th }} \text { week of } \\
\text { pregnancy }\end{array}$} \\
\hline \multicolumn{4}{|l|}{ Care of the Newborn after delivery } \\
\hline By the respondent/ family & 103 & & $(85.1)$ \\
\hline Adoption/ foster care & 14 & & $(11.6)$ \\
\hline Not applicable (baby died ) & 1 & & $(0.8)$ \\
\hline No information & 3 & & (2.5) \\
\hline
\end{tabular}

Table IV shows the sexual history/ information of the patients as well as the contraceptive information, STIs awareness, and the awareness of the availability of the support group. Majority of the respondents has their first sexual exposure during their teenage years $(61.9 \%)$, and $25.6 \%$ has two or more sexual partners.
Only $8.3 \%$ has history of being sexually assaulted. 92 patients $(76 \%)$ never used any contraceptive method despite majority of them $(85.1 \%)$ were aware of the danger of sexually transmitted disease. Of all the atients, about $45 \%$ were not aware of availability of support groups. 
Table IV. Sexual history, contraceptive method and HIV awareness

\begin{tabular}{|c|c|c|}
\hline Criteria & $\mathbf{N}$ & $(\%)$ \\
\hline \multicolumn{3}{|l|}{ Age at first sexual exposure (years) } \\
\hline$<20$ & 75 & $(61.9)$ \\
\hline $20-24$ & 38 & $(31.4)$ \\
\hline $25-29$ & 6 & $(5.0)$ \\
\hline$>30$ & 1 & $(0.8)$ \\
\hline No information & 1 & $(0.8)$ \\
\hline \multicolumn{3}{|l|}{ No. of sexual partner } \\
\hline 1 & 86 & $(71)$ \\
\hline 2 or more & 31 & $(25.6)$ \\
\hline No information & 4 & $(3.3)$ \\
\hline \multicolumn{3}{|c|}{ Prior history of being sexually assaulted/ molested } \\
\hline Yes & 10 & $(8.3)$ \\
\hline No & 111 & (91.7) \\
\hline \multicolumn{3}{|l|}{ Contraception ever used } \\
\hline Yes & 29 & $(24)$ \\
\hline No & 92 & (76) \\
\hline \multicolumn{3}{|l|}{ Contraceptive method ever used } \\
\hline Coitus Interruptus & 6 & (5) \\
\hline Barrier method & 12 & $(9.9)$ \\
\hline Oral Contraceptive Pill & 8 & $(6.6)$ \\
\hline Intramuscular depo provera & 1 & $(0.8)$ \\
\hline More than one method & 2 & $(1.7)$ \\
\hline Other method & 0 & $(0)$ \\
\hline Never used any method & 92 & (76) \\
\hline \multicolumn{3}{|l|}{ HIV awareness } \\
\hline Yes & 103 & $(85.1)$ \\
\hline No & 18 & $(14.9)$ \\
\hline Yes & 103 & $(85.1)$ \\
\hline No & 18 & (14.9) \\
\hline \multicolumn{3}{|l|}{ Support group awareness } \\
\hline Yes & 64 & (52.9) \\
\hline No & 54 & (44.6) \\
\hline No information & 3 & $(2.5)$ \\
\hline
\end{tabular}

\section{DISCUSSION}

This study demonstrated that single unmarried women in the centre are associated with disadvantage sociodemographic background. A large proportion of the women involve adolescent mothers $(31.4 \%)$ which are similar to previous reports from different centers. ${ }^{10}$ This requires special attention as adolescent mothers tend to be psychologically immature and tend to practice unsafe sex and conceive. A study among adolescents in secondary school have shown that only $37.7 \%$ of them realize that the vagina is the organ for sexual intercourse and only $30 \%$ of them believe that pregnancy is possible after one act of sexual intercourse. ${ }^{11}$ This lack of sexual knowledge of the very basic aspect warrant special attention and action from the responsible authority especially with regards to providing adequate reproductive health education. However, findings of Anwar and colleagues noted that students who claimed to be sexually active were more knowledgeable than those who never had sexual intercourse. ${ }^{12}$

This study also showed poor contraceptive uses despite the awareness about HIV. This could be due to lack of preparation prior to the 'sexual event' or lack of self empowerment in dealing with their sexual partner especially with regards to the use of barrier method. It has been noted that knowledge and use of condoms is low and many adolescents would not insist on using condom to protect themselves from HIV/AIDS. ${ }^{13}$ Even among married women, there is a high rate of unintended pregnancies in Malaysia due to low contraceptive use whereby only $30 \%$ use modern contraceptive use. ${ }^{14}$ 
Study by Wong also noted that reproductive health knowledge and attitudes were intricately linked to religious values and cultural norms differences surrounding sexual issues. ${ }^{15}$ Awareness and action taken as preventive measure against STI is very important as these women are considered in a high risk group, and women and girls are increasingly getting infected with HIV, constituting $21 \%$ of newly infected persons in 2011 compared to only $5 \%$ ten years previously. 4.16 Wong in his qualitative inquiry into premarital sexual behaviours and contraceptive use among multiethnic young women has concluded that it is important to develop culturally specifiv interventions that address the identified promoting factors of premarital sex. Behavioral interventions to promote condom use should also increase awareness about condom effectiveness against not only unwanted pregnancies but also STIs. ${ }^{17}$

Some studies have highlighted the importance of antenatal care in reducing the risks of pregnancy. ${ }^{6,18,19}$ The unmarried women in our study did not take advantage of the widely available universal access to healthcare services nationwide as shown by the fact that about $70 \%$ of them did not book their pregnancy at all, or booked their pregnancy late. This could be due to lack of awareness of the services available in the community, and a lack of knowledge regarding the importance of early and regular care. In view of the stigma of being an unmarried mother, the main reason could also be their preferences to conceal their pregnancies. The promotion of early and comprehensive antenatal care is therefore an essential strategy in order to ensure the maternal-fetal well being. This must be done in such a way so that this group of patients will come forward for the appropriate care. Nationwide, 25\% unmarried adolescent registered at the Ministry of Health primary care facilities for their antenatal check up in July to December 2010. ${ }^{4}$

Most of the women and their family come from a poor socioeconomic group as indicated by their poor monthly income. Strengthening the moral, religious belief and family institution by identifying influencing factors and to develop as well as promote family and parenting programmes would undoubtedly be able to produce responsible citizens.

There are several limitations in our study. First and foremost is that it involved only one main government hospital in Pahang, and women delivered at private hospitals or maternity centers were not included. There is also no comparative study performed between married and unmarried women which are important in determining the significance of the findings. This could be assessed in future studies. In addition, recall bias may have occurred during data collection - some cannot even provide the information required. In view of the sensitivities of some of the questions also, some of the women may not answer the questionnaire truthfully.

Undoubtedly the data from this study could be the tip of an iceberg as a number of unmarried mothers preferred to deliver at private centers, or even in places with no experience birth attendance. However, it may provide us some insight at the professional level to help the patient directly or indirectly, and to create prevention strategies in order to pave the way towards a better ummah. Further follow up, support and care should be offered to these women either to help them cared for their babies, or in offering alternatives to the care of the baby to avoid baby dumping as well as the care of the women's well being. The seriousness of baby dumping in Malaysia has led to the set up of OrphanCARE - an NGO which was started in 2008 to help expedite the adoption process for abandoned babies and children in orphanages. 'Baby hatches' centre has also been conceived in order to save the lives of the unwanted babies.

It is of great intention that this research will pave the way towards a better and more sensitive way in dealing and addressing the female gender in the community ideally prior to them being involved in any sexual activity. With the information at hand, community-based projects especially with regards to disseminating optimum women health care can be handled more effectively.

\section{CONCLUSION}

Single unmarried women are associated with disadvantaged sociodemographic profile. Contraceptive practice was also very low despite significant awareness towards risk of HIV infection. Further follow up, support and care should be offered without prejudice.

\section{ACKNOWLEDGEMENT}

This study was supported by International Islamic University Malaysia (IIUM) Endowment Fund Type A.

\section{Conflict of interest}

The authors declare that they have no conflict of interest.

\section{REFERENCES}

1. Lim Wey Wen. Baby dumping cases escalate [online].Available at: http://thestar. com. my/news/story. asp?file=/2012/7/6/ nation/11612591\&sec=nation. Accessed October 29, 2012.

2. Wang B, Li X, Stanton B, et al. Sexual attitudes, pattern of communication, and sexual behavior among unmarried out-of-school youth in China. BMC Public Health 2007; 7:189.

3. Shawky S, Milaat W. Early teenage marriage and subsequent pregnancy outcomes. East Mediterr Health J 2004; 6:46-54.

4. Statement by Mr Harjeet Singh, Deputy Secretary General (strategic), Ministry of women, family and community development; representative of Malaysia at the 45th session of the commission on population and 
development at the general debate on national experience in population matters: adolescents and youth, New York, 24 April 2012.

Available at: http://www.un.int/ malaysia/ GA/66/66unga75_CPD_Youth.pdf. Accessed October 30, 2012.

5. Luo Z-C, Wilkins R, Kramer MS. Disparities in pregnancy outcomes according to marital and cohabitation status. Obstet Gynecol 2004; 103:1300-7.

6. M Kamarul Bahyah, AW Noraziana, MA Norhuda, A Mokhtar. 3 year review of eclampsia cases in Hospital Tengku Ampuan Afzan, Kuantan. Malaysian Journal of Obstetrics and Gynecology 2010; 8:19(suppl):28.

7. Badiah Y, Mohd Jamil BHY. Infanticide. Malaysian Journal of Psychiatry 2006; 15:3-10.

8. Bureau of Justice Statistics, US Department of Justice. Homicide trends in the United States: infanticide. Available at: www.ojp.usdoj.gov/bjs/ homicide/children.cfm. Accessed October 30, 2012

9. Friedman SH, Resnick PJ. Child murders by mothers: patterns and prevention. World Psychiatry 2007; 6:137-41.

10. Omar K, Hasim S, Muhammad NA, et al. Adolescent pregnancy outcomes and risk factors in Malaysia. Int J Gynecol Obstet 2010; 111: 220-3.

11. Ab Rahman A, Ab Rahman R, Ibrahim MI, et al. Knowledge of sexual and reproductive health among adolescents attending school in Kelantan, Malaysia. Southeast Asian J Trop Med Public Health 2011; 42:717-25.

12. Anwar M, Sulaiman SA, Ahmadi K, Khan TM. Correction: Awareness of school students on sexually transmitted infections (STIs) and their sexual behavior: a cross-sectional study conducted in Pulau Pinang, Malaysia. BMC Public Health 2010; 10:571.

13. Sexual and reproductive health of adolescents and youths in Malaysia. A review of literature and projects 2005. WHO Western Pacific Region. Available at: http://www.wpro.who.int/ publications/docs/ASRHmalaysia.pdf. Accessed October 30, 2012

14. Najafi F, Rahman HA, Hanafiah M, Momtaz YA, Ahmad Z. Emergency contraception: knowledge, attitudes and practices among married Malay women staff at a public university in Malaysia. Southeast Asian J Trop Med Public Health 2012; 43:1512-20.

15. Wong LP. An exploration of knowledge, attitudes and behaviours of young multiethnic Muslimmajority society in Malaysia in relation to reproductive and premarital sexual practices. BMC Public Health 2012; 12:865.

16. Millenium Development Goals (MDG) 6 Combat HIV/AIDS, Malaria, and other diseases. Available at: http://www.undp.org.my/uploads/mdg6.pdf. Accessed October 30, 2012.

17. Wong LP. Qualitative inquiry into premarital sexual behaviours and contraceptive use among multiethnic young women: implications for education and future research. PLoS One 2012; 7(12):e51745. Doi:10.1371/journal.pone.0051745. Epub 2012. Dec 14. Accessed November 28, 2012

18. Mahavarkar SH, Madhu CK, Mule VD. A comparative study of teenage pregnancy. J Obstet Gynaecol 2008; 28:604-7.

19. Nadarajah S, Leong NK. Adolescent pregnancies managed at KK Hospital. Singapore Med J 2000; 41:29-31. 